Indonesian Journal of EFL and Linguistics

Vol. 4 No. 1, 2019

eISSN: 2503-4197, pISSN: 2527-5070

www. indonesian-efl-journal.org

\title{
Teacher's Reinforcements Affecting Students' Willingness to Communicate (WTC): A Photovoice in EFL Classroom
}

\author{
Bimo Teguh Prasetyanto ${ }^{1)}$ \\ Department of English Education \\ Universitas Sebelas Maret \\ e-mail: bimoteguhp@gmail.com \\ Diyah Ayu Wibawani ${ }^{2}$ \\ Department of English Education \\ Universitas Sebelas Maret \\ e-mail: wibawaniayudiyah@gmail.com \\ Erika Novia Wardani ${ }^{3}$ ) \\ Department of English Education \\ Universitas Sebelas Maret \\ e-mail: erikanoviawardani@gmail.com \\ Nur Arifah Drajati ${ }^{4)}$ \\ Department of English Education \\ Universitas Sebelas Maret \\ e-mail: Nurarifah_Drajati@staff.uns.ac.id
}

\begin{abstract}
:
In teaching English, a teacher should stimulate students' activeness to engage in a class. One way to do it is by giving reinforcement. A good reinforcement has a significant role in the students' speaking activeness. It can be a source of students' motivation to learn and in this case, their activeness to speak in class. This research
\end{abstract}


Bimo Teguh Prasetyanto, et al

aims to discover what reinforcement that triggers students' willingness to communicate. The result is intended to discover the effects of teacher's reinforcement towards students' willingness to communicate. The data for this research is collected by the photovoice method in which more practical is needed by collaborating with SHOWeD in analyzing the data. The participants of this research are 28 college students, consisting of 7 male students and 21 female students ranging from 19 to 21 years old in English Education Department who are currently attending college. Based on the data analysis, the finding of the research is teacher reinforcement in EFL classroom affect students' willingness to communicate, particularly selfconfidence, interpersonal motivation, and intergroup motivation. The research implied to help teachers to understand more about the way teacher's reinforcement affect the students' speaking activeness seen from the students' perspective.

Keywords: Photovoice, EFL Classroom, Teacher's reinforcements, Willingness to Communicate (WTC)

\section{INTRODUCTION}

According to Krause and Coates (2008), engagement is taken to provide a singularly sufficient means of determining whether students are engaging with their study in ways likely to promote high-quality learning. Thus, in language learning, the students need to have interaction to practice their target language. Skehan (1989) argues that learners' talk in the target language is fundamental to achieve L2 proficiency. Hence the learning process should place more emphasis on how to utilize classroom tasks largely to encourage students to demonstrate their linguistic competence within conversations. Cao and Philp (2006) as cited in Vongsila and Reinders (2016) said that speak up in the classroom is not easy depending on the situation they are in. As cited in Vongsila and Reinders (2016), anxiety and perceived competence (MacIntyre et al., 1999), communication confidence (Peng and Woodrow, 2010), classroom conditions, group cohesiveness and topic relevance (Aubrey, 2011) are identified as situational variables that affect Willingness to Communicate.

Willingness to communicate is defined by McCroskey and Baer (1985) as a readiness to enter into discourse at a particular time with a specific person or people, using a second language. Another study by Long (2015) says that language learning and language use should move in concert with each other. It means that language learned through meaningful communication, and language use should mediate language learning. When the need arises, specific forms should be attended to but in context and within communicative tasks. The common problem is, on some occasions, the students tend to be silent when they feel intimidated by the situation of the class. To reduce their nervousness, a teacher can give compliments or encouragement to the students. As cited in Mohammad Amiryousefi (2016), Interest and motives to 
communicate with the teacher are recognized to influence students' motivation for learning, involvement with the learning tasks, and educational.

Miller (2006) argues that reinforcement is the procedure of utilizing a reinforcer to increase the rate of behavior. A reinforcer is any event or stimulus that follows a behavior firmly in time and increase the frequency of that behavior. Teachers' reinforcement needs to be frequent enough to stimulate the students' willingness to communicate. Establishing how frequently the reinforcement provided is important. Too much reinforcement in a short period may cause the student to be tired of it; thus the reinforcement becomes less effective. According to Skinner (1958), any organism continues to do a certain behavior, expecting to be rewarded in the reason for what they do. The action of rewarding, in this case, can be categorized as reinforcement. However, if the reinforcement is delayed, the subject may stop doing the behavior altogether. Considering the two important aspects of willingness to communicate and reinforcements by the teacher to create an active learning process, conducting this research will provide information related to those based on the class observation. Moreover, in Indonesia, a study which relates between the willingness to communicate and the teacher's reinforcements has not been investigated by any researcher. Conducting this research by using the photovoice method and seeing from students' perspective will be the gap of this research.

Related to the background of the study, the problem of the question is as follows: "Does teachers' reinforcement affect students' willingness to communicate?"

\section{LITERATURE REVIEW}

Khajavy et al. (2017) mentioned teacher's support in the form of positive reinforcement influence the class condition. By giving positive reinforcement to the students, the teacher adds appetitive stimulus following correct behavior. Reinforcement increases the right behavior, which in this study students' willingness to communicate is good behavior. According to Skinner's Reinforcement theory (1958), individual behavior is a function of its consequences. Reinforcement theory includes four approaches, positive reinforcement, negative reinforcement, extinction, and punishment. Positive reinforcement in the classroom context is when students work well and do some enthusiasm in the study then the teacher give a reward to encourage and motivate the student. Giving positive reinforcement in the classroom will result in students' actions such as having the willingness to communicate.

Classroom interaction patterns have been shown to have a significant influence on the type and frequency of student talk and as such is likely to have a significant impact on willingness to communicate (Vongsila and Reinders, 2016). To communicate means to speak, to declare and to state the ideas. Learning activities that require students to speak up become a problem when there is no willingness from the learner to communicate in learning activity process. Willingness to communicate (WTC) in the second language is an important variable of interest. According to Macintyre et al. 
Bimo Teguh Prasetyanto, et al

(1998), WTC refers to the inclination of initiating communication in the L2 when having a free choice to do so.

Willingness to Communicate (WTC) by Macintyre et al. (1998) has six layers. Layer I: Communication behavior, related to L2 use. Layer II: Behavioral intention, related to willingness to communicate. Layer III: Situated antecedents, related to desires to communicate with a specific person and state communicative self-confidence. Layer IV: Motivational propensities, related to interpersonal motivation, intergroup motivation, and self-confidence. Layer V: Affective cognitive-context, related to intergroup attitudes, social situation, and communicative competence. Layer VI: Social and individual context, related to intergroup climate and personality. WTC facilitates the development of interpersonal relationships with teachers.

The interpersonal relationship also depends on what the teachers say to their students daily and in the classroom. Teachers who often give compliments and encouragement in the classroom will be likely to be more successful in establishing a close relationship with their students. Thus, making the students more interested in contributing by speaking. Another antecedent is learner beliefs or perceptions. Peng and Woodrow (2010) as cited by Dangyao (2018) proposed that learners' beliefs and value judgment about learning English language and classroom communication gave effects on learners' attitudes and behaviors. The findings of the research tell that learners' beliefs indirectly predicted WTC through motivation and confidence.

\section{RESEARCH METHODOLOGY}

\subsection{Research design}

Photovoice is action research where people can analyze, show, and improve their society using a specific photographic technique according to Wang and Burris (1997, p. 369). It is a participatory method that has participants use photography, and stories about their photos to identify and represent issues of importance to them, which enables researchers to have a greater understanding of the issue under study (Wang, 2010). The author researches by doing several steps in photovoice methods such as observation by taking the photos of the participants, questionnaire, and supported with interviews to get the valid data.

\subsection{Participants}

The participants of this study are 28 students of English Education Department of a University in Indonesia who are in their third year of college. There are seven males students and 21 female students. The age range of these participants is 19 to 21 years old. The reason of choosing these students as the participants of the research was that they were familiar enough with EFL setting to be able to answer the research instrument and thus they are expected to be reliable participants of the research. 


\subsection{Data Collection and Analysis}

The data of this research is taken by adapting the photovoice method. The students are asked to fill the questionnaire and tell their background story of the photo. The instrument of the study uses Instructional Willingness to Communicate (IWTC).

In the photovoice, the classroom condition is described as the analysis of photos of the activities which confirmed by giving questionnaire and asking in the interview session. The written document, questionnaire, and the data from the interview session were collected as the data. This research was conducted in around 14 weeks in a college English classroom. The activities that the researchers observed were the class activeness while the students are having a project to discuss in a group. The group presentation in front of the class was given some feedback from the audiences and vice versa. SHOWeD analysis method (Wang and Burris, 1997) was used by the researchers to analyze the questionnaire. SHOWeD is the acronyms five points in the questionnaire that should be answered by the participants while analyzing the photos.

$$
\begin{aligned}
& \text { S - What do you see here? } \\
& \text { H - What is really happening here? } \\
& \text { O- How does it relate to our lives? } \\
& \text { W - Why does the situation happen? } \\
& \text { e- How could this image educate the class? } \\
& \text { D - What can we do as the students about it? }
\end{aligned}
$$

These questions aim to "identify the problem or the asset, critically discuss the roots of the situation and develop strategies for improving the situation" (Wang, 1999). These questions can be utilized to (a) understand the more profound structural matters in which experiences are embedded and the processes that maintain or uphold the status quo and (b) the actions that can be taken to carry about meaningful change as well as the resources available to engage in these change processes.

Besides using SHOWeD analysis in the photovoice method, the researchers also adopt the IWTC Scale by Khatib and Nourzadeh (2014) which will help in collecting and analyzing data. IWTC Scale (Khatib and Nourzadeh 2014) was used to assess the participants' L2 WTC. This instrument contains 28 items that are classified under six major categories for measuring: (1) communicative self-confidence (a learner's positive evaluation of his/her ability to produce and understand messages in L2 fluently and efficiently); (2) integrative orientation (a learner's positive attitudes toward L2 culture); (3) situational context of L2 use (immediate situational variables in the instructional context that have momentary impacts on learner's L2 WTC); (4) topical enticement (the extent to which the topic of spoken materials entices language learners to communicate); (5) learning responsibility (the extent to which the learner uses his/her L2 knowledge in communication to develop that knowledge further); and (6) off-instruction communication (learners' WTC with others when the process of instruction is not going on in an educational setting). Khatib and Nourzadeh (2014) 
developed and validated this questionnaire with 624 Iranian EFL learners as a measure of WTC for instructional language teaching and learning contexts. Its advantage over the previously developed and highly quoted questionnaires such as that of McCroskey (1992) is that it is specially developed for EFL contexts and sets researchers free of using the generic questionnaires. The participants were asked to rate the items based on the anchor points of $1=$ strongly unwilling, $2=$ unwilling, $3=$ neither willing nor unwilling, $4=$ willing, and $5=$ strongly willing. By using the IWTC scale, the data are collected from the participants. From all six categories above, the authors of this research choose three categories of factors. The first one is communicative selfconfidence. The second is the situational context of L2 use. The last is learning responsibility.

\section{FINDINGS}

The use of reinforcement in learning activity towards students' willingness to communicate has proven to have a significant impact. The students will feel motivated when the teachers are using certain reinforcement in the learning process. It is needed to stimulate students' learning motivation. However, the amount and the frequency of the reinforcement should be a concern for the teachers. The reason for that statement is giving either too much, or not enough reinforcement will make the reinforcement itself ineffective. Based on the interview and the questionnaires given to the participants, it is proven that students' willingness to communicate can be affected by teachers' reinforcement. In one of their class, the students would do a presentation and receive feedback from their friends from the other group. This activity is expected to trigger students' willingness to communicate among them. In this presentation activity, the students can give responses, critics or suggestion each other. Therefore, it requires the students to speak up, which requires motivation propensities which divided into three aspects: 1) interpersonal motivation 2) intergroup motivation and 3) self-confidence.

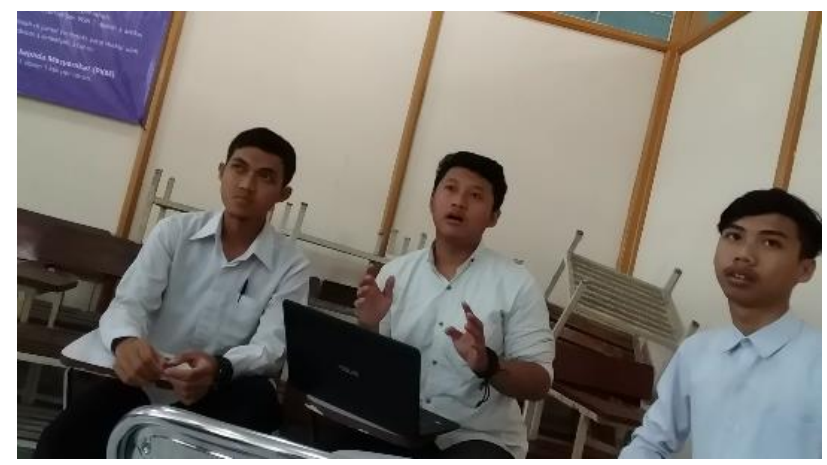

Figure 1. Interpersonal motivation to talk 
S - What do you see here?

A student is asking questions.

$\mathrm{H}$ - What is really happening here?

The student asks the teacher about the material they did not understand enough.

$\mathrm{O}$ - How does this relate to our lives? (or your life personally)

By asking questions to the teacher, the student will realize that he has interpersonal motivation. He has the willingness to communicate with others in order to fill the gap of information he has.

W - Why does the situation happen?

This situation happens because the student did not understand the material well and the teacher encourages all of the class to ask if they do not understand the explained material.

e - How could this image educate the class?

By looking at the image, the other students will be influenced to be more active in class. Looking at their friend has the courage to ask the teacher, the other students will have the courage too.

D - What can we do about it as students?

As students, we can increase our interpersonal motivation and decrease anxiety by asking the teacher if there is any information that we do not understand well. Interpersonal motivation leads the students to interact with others and earn the benefit of having interaction

Figure 1, based on SHOWeD analysis, after the presentation from the representative group, the other groups are given opportunities to ask anything related to the presentation. First, the representative will allow the volunteer to ask the questions. If there is no volunteer, the teacher will ask once again to courage the students to ask. By giving a question or comment to the representative, it indicates that the students are following the presentation. When there is no question or any comment, the teacher will give an inducement to the students. The inducement from the teacher can be in the form of reinforcement like this statement "Come on students, it is okay to ask or give any comment to the group. There will be a point for your group by giving a response". As a result, one of the groups is induced to ask and give their response to the representative.

Asking the teacher needs courage. The students should have motivation, courage, and self-confidence to interact with the teacher. Interacting with teachers in the classroom needs interpersonal motivation as well as asking the classmates. Interpersonal motivation is one of the aspects of motivation propensities which focus on the communication between one another human, the thing that makes someone having the willingness to communicate with the other. 
Bimo Teguh Prasetyanto, et al

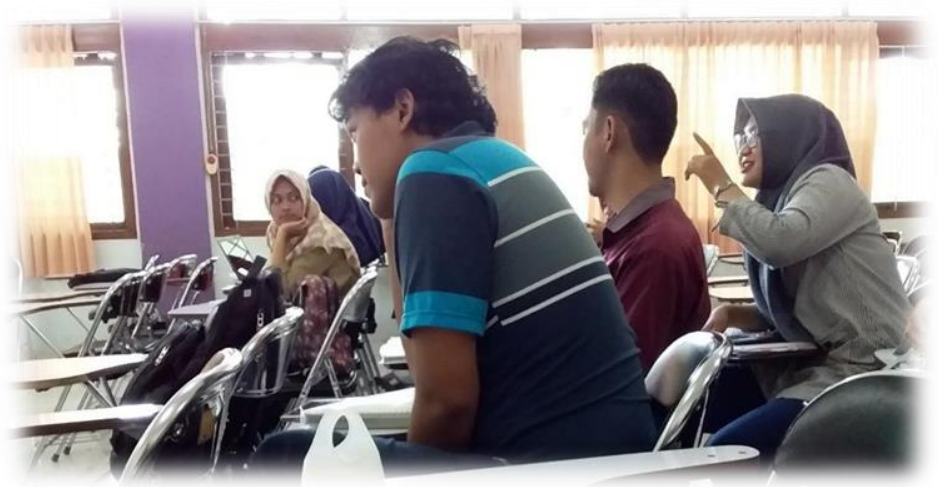

Figure 2. Intergroup activity

$\mathrm{S}$ - What do you see?

Answer: We are discussing project questions from the teacher and responding to the other group's work

$\mathrm{H}$ - What is really happening here?

Answer: Our teacher gives us some question to be answered related to the course and our job is discussing in group consists of 4-5 students then presenting the group work in front of the class and the other groups asked to respond the presenter group.

$\mathrm{O}$ - How does this relate to our lives?

Answer: From this activity, we have opportunities to convey our ideas in the group. Talking in the group, also will help us increasing self-confident as an exercise to talk in a bigger forum.

W - Why the situation, concern, or strength exist?

Answer: Because of talking to a big forum sometimes frightening us, by working and discussing in a group can be as an alternative to speak up for each group member.

Talking in a group is better than passive in a big forum. When we do a language mistake, the other group member will correct us kindly, and we are okay with that.

E - How this image EDUCATES the community?

Answer: By looking at the image, we can see that intergroup motivation can help us practicing to talk by showing our ideas and asking the other responses toward the performances. We get an evaluation from the group and it useful for better performance

D - What can we do about it?

Answer: we can use the small group platform to practice before talking in a bigger group.

Figure 2, based on SHOWeD analysis, we can see that by working in a group, the students' motivation will gradually appear. As a result, active communication will 
happen and support the learning process. When there is a good learning process, there will create a class environment which can motivate the students to speak in the class. The good performances by the other group will also motivate a group to show their best work too. From the picture, it can be seen that intergroup motivation also significantly influences the students' willingness to communicate in the group forum and class. By seeing the other performances, the students will be motivated to speak up and collect an excellent score of the activeness in the class.

Before conveying the ideas to the other group, a member of the group will get suggestions from the other member so when they are performing the result of the discussion will confidently that what they are saying are supported by the group. As a result, motivation to speak up in class appear and the students' anxiety to communicate to the other will be less than when they are conveying their ideas based on their own opinion only

After one group gives their response towards the representative, the teacher says "That is a very good comment and suggestion for the A's group, but .....". The teacher appreciates what the non-representative groups' response even though the response is notly accurate. By giving such kind of reinforcement, the teacher's comment will not cause the students to feel anxiety after getting a comment from the teacher. On the other hand, giving reinforcement to a group will stimulate the other groups to speak up when the discussion happens. This condition represents the willingness to communicate of students is influenced by the intergroup motivation and the teacher's reinforcement.

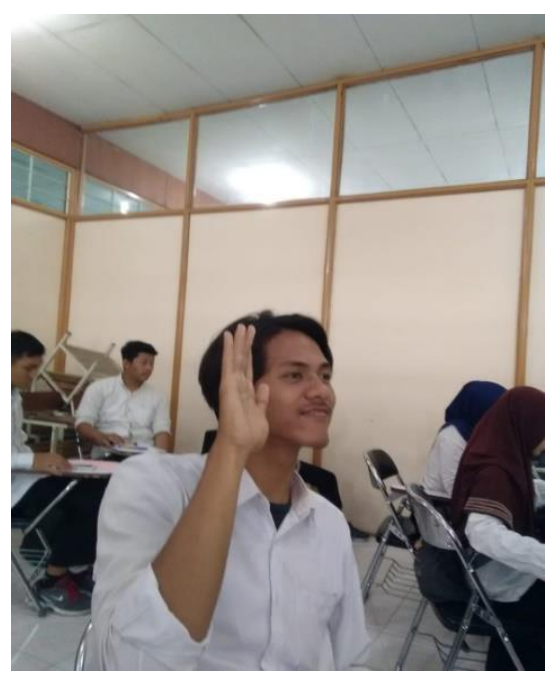

Figure 3. Speaking up in class 
Bimo Teguh Prasetyanto, et al

$\mathrm{S}-$ What do you see?

Answer: We are giving a response to our friends' presentation

$\mathrm{H}$ - What is happening here?

Answer: Our friends just finished their presentation, and they ask if there is any comment. We are volunteering ourselves give a response to ourselves which obligate us to speak up in the class.

$\mathrm{O}-$ How does this relate to our lives?

Answer: From this activity, we can know how much self-confident we have to give comments in which may be some language mistakes that we do. The language mistakes can hold us from giving responses.

W - Why the situation, concern, or strength exist?

Answer: Because of the chance to train our confidence comes and also many other friends encourage other classmates to speak up. Moreover, in the course we are in, we will get a new grade if we are active in class.

E - How this image EDUCATES the community?

Answer: By looking at the image, we can see that self-confidence is significant to make students show their willingness to communicate.

D - What can we do about it?

Answer: We can train our confidence by volunteering to speak up whenever the chance appears

In Figure 3, based on the SHOWeD analysis, one of the participants shows the role of self-confidence. Both aspects, perceived competence, and anxiety can be seen present at different levels. In the picture, it is most likely that the student has high perceived competence since he raises his hand confidently to give a response to his friends' presentation voluntarily. The anxiety level that can be seen in the picture is low since the student does not show any tension or express any fear in his facial expression and gestures.

Self-confidence is a motivational factor that comes from oneself without the interference of others. A student that has high self-confidence will be likely to be more active to speak up and say his opinion rather than those who do not have high selfconfidence. By having self-confidence, a student will also have a higher willingness to communicate than those who do not. Besides the self-confidence from the students themselves, the teacher treatment to the students is supporting them to be confident to communicate with the representative group in order to get further information from the presentation. The teacher stimulates the students, and it influences the students to speak without any anxiety among the students. 


\section{DISCUSSION}

The findings of this research show that teachers' reinforcement has effects on students' willingness to communicate. In particular, teachers' reinforcement affects three aspects of willingness to communicate. There are interpersonal motivation, intergroup motivation, and self-confidence. Each three of these aspects contribute to students' WTC in their unique ways as explained below.

Teacher reinforcements have proven effecting internal motivation of the students. It supports their Willingness to Communicate in the classroom. The kind of reinforcements given by the teachers can be in the form of positive affective feedback such as, appreciating students effort of their work and giving corrections without using punishing expressions.

The finding above is in line to Patterson's argument as cited in Macintyre et al. (2004), interpersonal motivation has two purposes. The purposes are control and affiliation control related to the communication aimed at giving a limitation to cognitive, effective, and behavioral freedom. One of the types is the task-related situation with example students and the teacher. When the teacher tells the students to do a specific task, the students will be more likely to do compared to when the students are left without any instruction to do a task. It proves the existence of the control aspect of interpersonal motivation.

The other aspect of interpersonal motivation is affiliation. Affiliation is the amount of interest of one individual to communicate with the other. It is caused by personal characteristics such as attractiveness, physical proximity, and repeated exposure. It can be said that the more attractive the teacher is, the more closely the teacher with the students, the more frequent the teacher meets the student, the more it is likely for the students to initiate communication with the teacher.

The students' willingness to communicate can also be harnessed by giving reinforcement to the students as groups. The authors of this research found that if a teacher compliment a group, the students in that particular group will feel motivated despite the compliment is directed to them as a group and not as individuals. It proves that the students integrate themselves to their group. As the result, the students will have a motivation to involve and having inteaction with the other group or the teachers and the willingness to communicate of the students will be created in this condition.

The finding above suits MacIntyre statement that intergroup motivation is derived directly from their belonging to a particular group, as opposed to playing a social role within a group. In the case of intergroup relation, motivation to control would result in the same type of communicative behaviors as the interpersonal situation (MacIntyre et al., 1998). Willingness to communicate also needed when the students are working in a group. Active communication influences group performances. Through a group discussion, the students could convey their ideas in a small forum. The small forum 
Bimo Teguh Prasetyanto, et al

like this makes the students' anxiety smaller than when the students talk to the teacher directly

The students' self-confidence plays a vital role in their willingness to communicate as individuals. The authors found that students who are given positive reinforcement individually show an increase in their self-confidence. The students seem to show low to no hesitation and are more relaxed.

Having no hesitation and being more relaxed fit a description by Clement $(1980,1986)$ that self-confidence includes two keys constructs: (1) perceived competence and (2) a lack of anxiety. These constructs represent enduring personal characteristics in Clement's opinion. A student who perceives his competence as decent or more will often show the sign of high self-confidence. Perceived competence is how high an individual estimate his capability to communicate effectively in particular moments. Students who have high perceived competence will often risk themselves doing things that may be frightening for other students, such as speaking up in class. It would arise when a student is in a familiar situation or a condition that has been encountered previously, provided the student has developed his language skills and knowledge. High perceived competence can also give them little to no anxiety.

Anxiety is the transient emotional reaction defined by feelings of tension and apprehension, accompanied by autonomic nervous system arousal as described by Spielberger (1983). The state of anxiety varies in intensity, and it fluctuates over time. The amount of anxiety a student is experiencing affects his self-confidence, the higher it is, the less confidence the student will have. Therefore, it will also affect the willingness to communicate. Anxiety may be increased due to many factors, such as unpleasant previous experiences, intergroup tension, increased fear of assimilation, and an increased number of people listening.

From the three figures above, can be seen that reinforcements from the teacher toward the students and their group stimulate them to communicate actively in class. When there are zero anxiety and many reinforcements from the teacher, this condition will create an active learning process in class. The willingness to communicate of the students appear clearly when the teacher gives good treatment and saying the reinforced-words towards the students. Interpersonal motivation, intergroup motivation, and the self-confidence play prominently in the students' willingness to communicate in class.

\section{CONCLUSION}

By looking at the result of the research, the authors can conclude that teacher's reinforcement does have a positive impact on students' willingness to communicate. One of the aspects that enhanced by teacher's reinforcement is students' motivation to communicate. Three motivational aspects can categorize the motivation itself. There are interpersonal motivation, intergroup motivation, and self-confidence. 
Interpersonal motivation can be enhanced by teachers when the students are trying to interact with the teachers and their friends. This particular motivation mostly comes when the students ask other people, in the case of learning, their teachers and friends. Asking requires the students to initiate the act and have to perform their questions orally to gain the answer they want. While performing this, students might feel anxious or worried if they make mistakes. However, after they ask their friends or teachers, they will realize that they get interpersonal motivation moreover if the teachers give a compliment of what the students do. Their behavior will receive feedback and thus enhanced. Asking question then becomes familiar to the students, and they will be more motivated to initiate communication.

Intergroup motivation also plays a significant role in students' willingness to communicate. When students perform in a group, their anxiety will decrease in a significant amount making it possible for them to develop a higher desire to speak up. Teachers who actively promote this activity and give support to students who frequently being active in activities involving group communication will find the class is more dynamic. The students' willingness to communicate is increased due to the presence of their friends in groups and also the given reinforcement by the teachers.

Meanwhile, self-confidence is the aspect of students' motivation to communicate that comes purely from the students themselves. Students can be confident if they fulfill two conditions. First, if they perceive their capability to communicate is higher than it is. Second, if they are free of anxious feelings, the students can get help from teachers to boost their self-confidence by receiving reinforcement. Teachers' reinforcement will give support to the students and give them a better perception of their competence. The anxiety that the students are experiencing can also be soothed if the teachers give sufficient reinforcement. In the case of self-confidence, the interaction that teachers need to give reinforcement tends to be more personal to one particular student rather than spread out to the whole class.

\section{REFERENCES}

Altman, K. I., \& Linton, T. E. (1971). Operant conditioning in the classroom setting: A review of the research. Journal of Educational Research, 64(6), 277-286. https://doi.org/10.1080/00220671.1971.10884161

Amiryousefi, M. (2018). Willingness to communicate, interest, motives to communicate with the instructor, and L2 speaking: a focus on the role of age and gender. Innovation in Language Learning and Teaching, 12(3), 221-234. https://doi.org/10.1080/17501229.2016.1170838

Bernales, C. (2016). Towards a comprehensive concept of Willingness to Communicate: Learners' predicted and self-reported participation in the foreign language classroom. System, 56, 1-12. https://doi.org/10.1016/j.system.2015.11.002 
Bimo Teguh Prasetyanto, et al

Cao, Y. K. (2014). A Sociocognitive Perspective on Second Language Classroom Willingness to Communicate. TESOL Quarterly, 48(4), 789-814. https://doi.org/10.1002/tesq.155

Clement, Richard. (1980). Ethnicity, Contact and Communicative Competence in Second Language. Social Psychological Perspectives, 147-154. https://doi.org/10.1016/B978-0-08-024696-3.50027-2

Khajavy, G. H., Ghonsooly, B., Hosseini Fatemi, A., \& Choi, C. W. (2016). Willingness to Communicate in English: A Microsystem Model in the Iranian EFL Classroom Context. TESOL Quarterly, 50(1), 154-180. https://doi.org/10.1002/tesq.204

Khajavy, G. H., MacIntyre, P. D., \& Barabadi, E. (2018). ROLE of the EMOTIONS and CLASSROOM ENVIRONMENT in WILLINGNESS to COMMUNICATE. Studies in Second Language Acquisition, 40(3), 605-624. https://doi.org/10.1017/S0272263117000304

Khatib, M., \& Nourzadeh, S. (2015). Development and validation of an instructional willingness to communicate questionnaire. Journal of Multilingual and Multicultural Development, 36(3), 266-283. https://doi.org/10.1080/01434632.2014.914523

Krause, K. L., \& Coates, H. (2008). Students' engagement in the first-year university. Assessment and Evaluation in Higher Education, 33(5), 493-505. https://doi.org/10.1080/02602930701698892

MACINTYRE, P. D., CLÉMENT, R., DÖRNYEI, Z., \& NOELS, K. A. (2011). Conceptualizing Willingness to Communicate in an L2: A Situational Model of L2 Confidence and Affiliation. The Modern Language Journal, 82(4), 545-562. https://doi.org/10.1111/j.1540-4781.1998.tb05543.x

McCroskey, J. C. (1992). Reliability and Validity of the Willingness to Communicate Scale. Communication Quarterly, 40(1), 16-25. https://doi.org/10.1080/01463379209369817

Miller, W. R., Moyers, T. B., \& Miller, W. R. (2015). Eight Stages in Learning Motivational Interviewing Eight Stages in Learning Motivational Interviewing, 2705(November), 37-41. https://doi.org/10.1300/J188v05n01

Munezane, Y. (2015). Enhancing willingness to communicate: Relative effects of visualization and goal setting. Modern Language Journal, 99(1), 175-191. https://doi.org/10.1111/modl.12193

Patterson, M. L., \& Ritts, V. (2016). Social and Communicative Anxiety: A Review and Meta-Analysis. Annals of the International Communication Association, 20(1), 263-303. https://doi.org/10.1080/23808985.1997.11678944

Pawlak, M., \& Mystkowska-Wiertelak, A. (2015). Investigating the dynamic nature of L2 willingness to communicate. System, 50, 1-9. https://doi.org/10.1016/j.system.2015.02.001

Peng, J. E., \& Woodrow, L. (2010). Willingness to communicate in English: A model in the Chinese EFL classroom context. Language Learning, 60(4), 834-876. https://doi.org/10.1111/j.1467-9922.2010.00576.x 
Roberts, L., \& Meyer, A. (2012). Individual Differences in Second Language Learning: Introduction. Language Learning, 62, 1-4. https://doi.org/10.1111/j.1467-9922.2012.00703.x

Shimshock, K., Gant, L. M., Hollingsworth, L. A., Allen-Meares, P., Miller, P., Shanks, T., \& Smith, L. (2009). Effects of Photovoice: Civic Engagement Among Older Youth in Urban Communities. Journal of Community Practice, 17(4), 358-376. https://doi.org/10.1080/10705420903300074

Spielberger, C. D., Gorsuch, R. L., Lushene, P. R., Vagg, P. R., \& Jacobs, A. G. (1970). Manual for the State-Trait Anxiety Inventory. Manual for the State-trait Anxiety Inventory STAI, 4-6. https://doi.org/10.1002/9780470479216.corpsy0943

Tan, D., Yough, M., \& Wang, C. (2018). International students in higher education. Journal of Applied Research in Higher Education, 10(4), 430-442. https://doi.org/10.1108/jarhe-01-2018-0008

Vongsila, V., \& Reinders, H. (2016). Making Asian Learners Talk: Encouraging Willingness to Communicate. RELC Journal, 47(3), 331-347. https://doi.org/10.1177/0033688216645641

Wang, Chilin. (2010). Toward a Second Language Socialization Perspective: Issues in Study Abroad Research. Foreign Language Annals Volume 43, Issue 1: https://doi.org/10.1111/j.1944-9720.2010.01059.x

Wang, C \& Burris, B.A (1997). Photovoice: Concept, Methodology, and Use for Participatory Needs. SAGE Journal, 24(3), 369387.https://doi.org/10.1177/109019819702400309 